Available online at:

https://acta-acustica.edpsciences.org

\title{
Influence of road traffic noise peaks on reading task performance and disturbance in a laboratory context
}

\author{
Catherine Lavandier ${ }^{1, *}$ (D), Mehdi Regragui ${ }^{1,2}$, Romain Dedieu ${ }^{1}$ (D), Carine Royer ${ }^{3}$ (D), and Arnaud Can $^{2}$ (I) \\ ${ }^{1}$ Laboratoire ETIS, CY Cergy Paris University, ENSEA, CNRS, UMR8051, 95000 Cergy, France \\ ${ }^{2}$ UMRAE, Univ Gustave Eiffel, IFSTTAR, CEREMA, 44340 Bouguenais, France \\ ${ }^{3}$ Laboratoire Paragraphe EA349, CY Cergy Paris Université, 95000 Cergy, France
}

Received 30 March 2021, Accepted 13 December 2021

\begin{abstract}
The influence of fluctuating road traffic noise on perceived disturbance during a reading task as well as on performance, inside a living room with closed windows, is presented in this paper. Sixteen 2-min sound sequences were created combining two variables: the number of events (four levels varying from one to four car pass-bys) and the peak emergence above the background noise (four levels with a $5 \mathrm{~dB}(\mathrm{~A}) \mathrm{step}$ ) keeping limited variations of $L_{\mathrm{Amax}}$, 1s. The noise impact was evaluated through a reading task of texts synchronized with the sound sequences, for participants classified into fast or slow readers, and sensitive or nonsensitive to noise. The comprehension rate of the texts decreases as the background sound level increases. The reading speed decreases during the rising front of a peak, and goes back to its former regular reading speed during the descending front of the peak. This slowdown during the rising front reaches $14 \%$ for slow readers. The declared disturbance is higher for slow readers compared to fast readers, and higher for noise sensitive persons compared to non-sensitive persons. The influence of the acoustic indicators on the reading disturbance is very small compared to the influence of personal factors. There is even no influence of the number of events on this disturbance.
\end{abstract}

Keywords: Noise disturbance, Reading task performance, Peak noise, Reading speed, Emergent events

\section{Introduction}

Environmental noise is recognized as one of the most important nuisances for citizens. The burden of disease from environmental noise has been quantified: sleep disturbance and annoyance are the largest health effects, with 903000 years and 654000 years disability-adjusted life-years in Europe, respectively largely before cardiovascular disease, cognitive impairment in children and tinnitus [1]. Moreover, sleep disturbance and annoyance mostly relate to road traffic noise. Even if aircraft noise is more annoying than road traffic noise for the same noise level [2], road traffic is cited by a majority of people as the most annoying noise source, since a large number of citizens are more exposed to road traffic noise than aircraft noise [3]. The acoustic indicators mainly used to evaluate the impact of road traffic noise are averaged indicators $[4,5]$. However, road traffic noise is known to vary with time [6]. Thus noise annoyance is impacted not only by the average noise level and the type of source, but also by the fluctuation of noise levels $[7,8]$. The pass-by of a single very noisy vehicle, can be a source of annoyance, especially in low-traffic areas, where the

*Corresponding author: catherine.lavandier@cyu.fr difference between background noise and emergences is high [9]. Then, indicators associated with the intermittent nature of the events such as their emergence or their number could complement classical averaged indicators [10-12]. This is accentuated during calm periods as night, when the background noise is low and events are rare [13, 14].

Annoyance is itself multi-factorial. Noise annoyance is defined by Guski et al. [15] as " $a$ psychological concept which describes a relation between an acoustic situation and a person who is forced by noise to do things she/he does not want to do, who cognitively and emotionally evaluates this situation and feels partly helpless". The annoyance felt by an inhabitant is described by Ouis [16] as "a feeling of discomfort, like a nuisance or irritation caused by particular sounds". Its process, described by Paunovic [17] and Miedema [18], can be defined as a form of psychological stress that triggers different personal resources when one is awake. As a consequence, when the particular sounds are repeated during long periods, noise annoyance has a very individual dimension, and a large part of it can be explained by extra-auditory factors [19]. Personal factors such as sensitivity to noise and situational factors such as the coping strategies an individual may develop when exposed to noise or the ability to mentally fade out the 
sound [20] are particularly influent. Based on literature study, Schreckenberg et al. [21] hypothesized that annoyance can be been divided into three dimensions: noiserelated disturbances, emotional and attitudinal responses to the sound, and perceived lack of coping capacity.

At a short time-scale, noise disturbs because it masks other sounds, makes intellectual activities difficult, disturbs attention and concentration, causes physiological arousal, and triggers negative emotional reactions. Then, to understand short-term annoyance related to noise peaks, it is interesting to look at the reactions of individuals to changes in noise levels over a short-time scale during an activity. The distracting effect of noise is particularly noticeable when the performed task requires memory work [22]. From a cognitive point of view, several studies show the impact of a noisy environment on concentration and the performance of a cognitive task (see [23] for a literature synthesis). Different mechanisms can occur when an unexpected sound event occurs, which can even stop the action of a listener under certain conditions [24].

In this paper, the perceived disturbance dimension of the annoyance due to fluctuating road traffic sounds is studied in a laboratory experiment. The negative effects of urban sound environments are studied through their cognitive impact and through the disturbance felt by the participants. During the experiment, participants were exposed to sound sequences that contained different numbers of car pass-bys with different levels of emergence, during a common reading activity in a laboratory mimicking a living room. Regarding the cognitive impact, the hypothesis is that fluctuating sounds, such as car pass-bys, can locally modify the reading speed of a text and globally change the ability to understand the read text. In addition, the relative influence of the acoustic characteristics of the sequences and individual participant factors on the disturbance to the reading task are investigated. Section 2 describes the methodology. The results of the experiment are presented in Section 3. Section 4 discusses the results and Section 5 elaborates conclusions on the consequences in terms of assessment of disturbance due to road traffic noise peaks.

\section{Methodology}

\subsection{Laboratory and apparatus}

The laboratory where the experiment took place is located in the housing part of "la Maison Internationale de la Recherche (MIR)" at CY Cergy Paris University (CYU). It is a second (and last) floor apartment designed to reproduce a sound environment in the centre of the living room [25]. For this experiment, three active loudspeakers (Yamaha HS7-I) were placed around the real closed window, facing the listener (Fig. 1). The experiment was conducted with the shutters closed to ensure that the natural variable light exposure of the laboratory would not influence the participants' responses. When there was no sound sequence reproduced through loudspeakers in the laboratory but with the three loudspeakers turned on, the equivalent sound level of the background was $20 \mathrm{~dB}$
(A). To avoid confusion between background noise of the sound sequences and background noise of the laboratory, this latter is called "silence" in this paper. The Vector Based Amplitude Panning (VBAP) technique was used to control the spatial distribution of the sounds with the loudspeaker gains [26]. The gains were set to simulate a traffic road noise coming from a closed double-glazed window (4-16-4 mm) in a second-floor apartment. As the sound sequences were generated with a software which uses monophonic sound files (see Sect. 2.2), there was no moving effect of a passby driving from one side to the other. The fixed localisation of the source was simulated from the bottom side of the window, in front of the participant.

\subsection{Sound sequences}

The sound sequences were simulated based on real road traffic sounds, in order to control their acoustical properties. The sequences consisted of background noise, to which were added a various number of car pass-bys, generated with the SimScene software [27]. SimScene ${ }^{1}$ is an open source library developed in Matlab that allows the simulation of sound scenes in a monophonic format as the additive composition of background and sound sources, using a database of recordings. In this study, the background noise corresponds to a continuous traffic flow that was recorded at $100 \mathrm{~m}$ from a urban motorway in Cergy (France), with the omnidirectional setting of a CMC6 Schoeps microphone on a portable recorder Tascam HD-P2. The car pass-bys were recorded with an ORTF system composed of two Schoeps CCM 4 microphones on a Tascam DR-100 near a two-line road in a very calm environment in Rezé (France). All isolated sound sources are very similar in terms of acoustic characteristics as they correspond to different pass-bys of the same car driving at the same constant speed and at the same distance from the recording point. In order to mix background noise (recorded in monophonic format) and isolated car pass-bys (recorded in stereo format) with the SimScene tool, stereo recordings were transformed into monophonic wave files by mixing the two channels with the Reaper ${ }^{2}$ software.

Sixteen 2-min sound sequences were created with the following characteristics of an outdoor environment based on a complete two factor design:

- Emergence of peak levels above the background noise in $\mathrm{dB}(\mathrm{A})$ calculated as the difference between $L_{\mathrm{Amax}, 1 \mathrm{~s}}$ and background noise $L_{\mathrm{A} 90}$. Four emergence levels were considered: $+10 \mathrm{~dB}(\mathrm{~A})$; $+15 \mathrm{~dB}(\mathrm{~A})$; $+20 \mathrm{~dB}(\mathrm{~A})$ and $+25 \mathrm{~dB}(\mathrm{~A})$.

- Number of peaks: 1;2;3 and 4. This corresponds to hourly traffic of between 30 and 120 vehicles per hour, which is representative of residential areas with low traffic volumes.

If one defines a pass-by event as the period when the sound level is above the threshold of $L_{\mathrm{Amax}}-10 \mathrm{~dB}(\mathrm{~A})$ $[28,29]$, one can assume that every peak in this study is a

\footnotetext{
${ }^{1}$ https://bitbucket.org/mlagrange/simscene

${ }^{2}$ https://www.reaper.fm/
} 


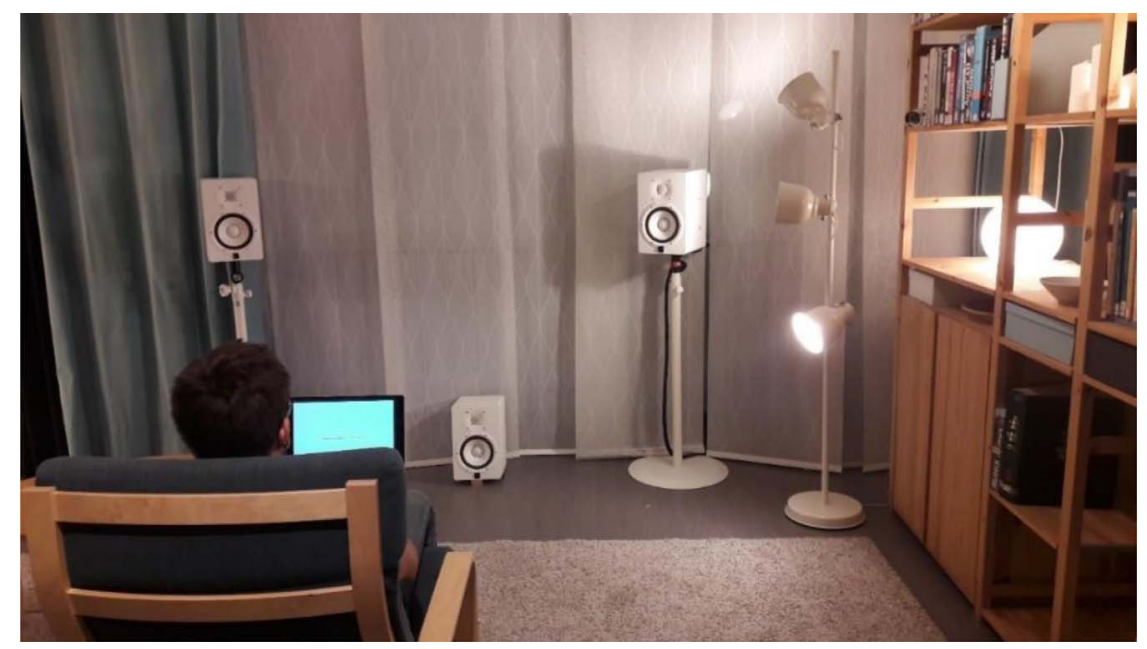

Figure 1. Picture of the experimental laboratory.

Table 1. Acoustic characteristics of the 16 sound sequences.

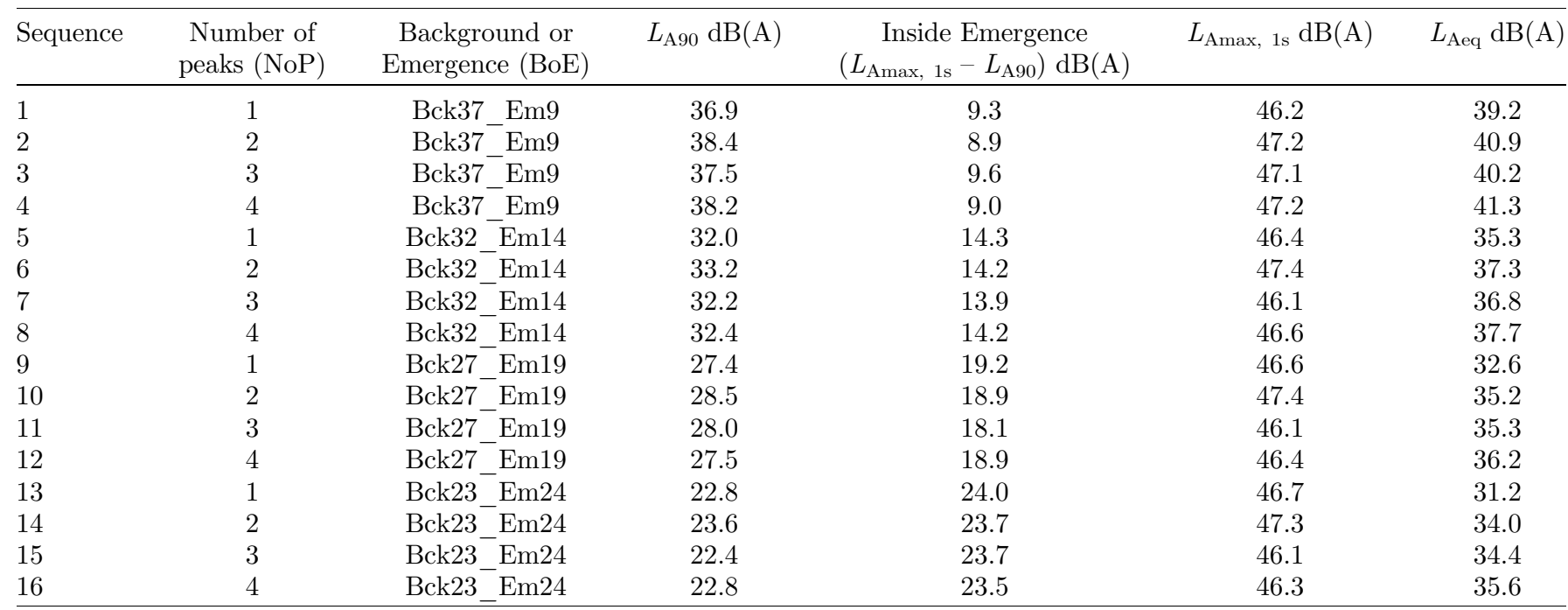

similar event for all the sequences whatever the background is. The sound sequences were then filtered through a conventional double-glazed window $(4-16-4 \mathrm{~mm})$ to create the sound spectrum expected within the room once windows are closed. The filter had an insulation of $30.7 \mathrm{~dB}$ at $100 \mathrm{~Hz}$ and 37.8 at $1 \mathrm{kHz}$. This operation modified a little bit the calculation of the inside emergence (Tab. 1).

The similarity between all $L_{\mathrm{Amax} \text {, 1s }}$ made the emergence values correlated with the background noise (Tab. 1). In order to ease the understanding of the results, the first factor is named "Background or Emergence" (BoE) with four levels (Bck23 Em24, Bck27 Em19, Bck32 Em14 and Bck37_Em9). The second is just named "Number of Peaks" (NoP) with four levels (1, 2, 3 and 4). Table 2 presents the third octave band spectra for a representative car pass-by and for a continuous traffic flow (background noise of the sequences 1 and 13 as examples).

The two extreme sound sequences are represented in Figure 2. These were the two sound sequences broadcasted during the training session of the test (see Sect. 2.3). Consequently, participants were exposed to the full range of the $(\mathrm{BoE})$ and $(\mathrm{NoP})$ parameter values at the beginning of the experiment before starting the test.

\subsection{Test protocol}

During the test, participants were exposed to the 16 sound sequences of $2 \mathrm{~min}$ each, meanwhile they were asked to read short texts. In details, four different texts were read during each sound sequence. In total, each participant read $4 \times 16$ different texts during the experiment. The presentation order of the texts was randomized. Each text was broken down into six lines. During the test, texts were scrolled line by line by the participant. Each line had a length of about six words. In order to measure the reading speed, texts and audio files were synchronized, and the reading time of each line was recorded. After having read a six-line text, participants had to answer two questions: 
Table 2. Inside third octave band spectra for a car pass-by calculated over $7 \mathrm{~s}$ and for the sequences 1 and 13 during the continuous traffic flow (background noise calculated over $7 \mathrm{~s}$ too).

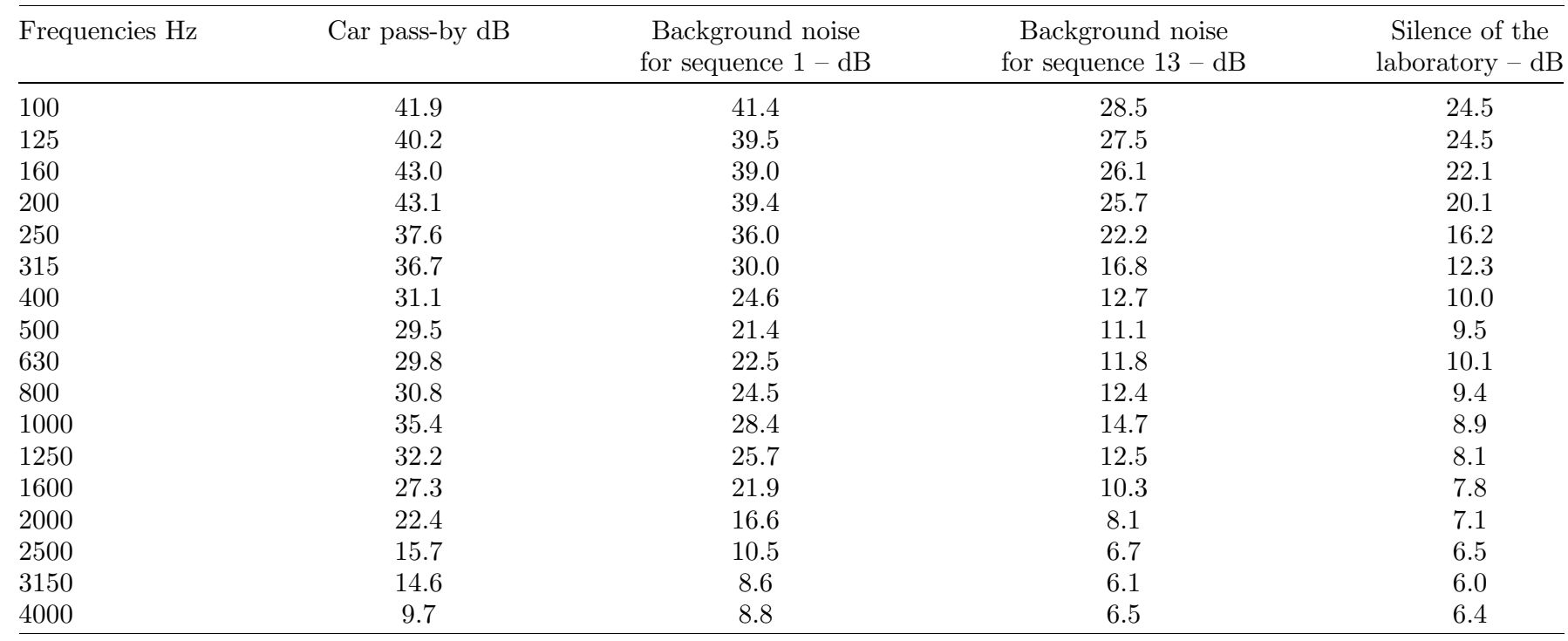
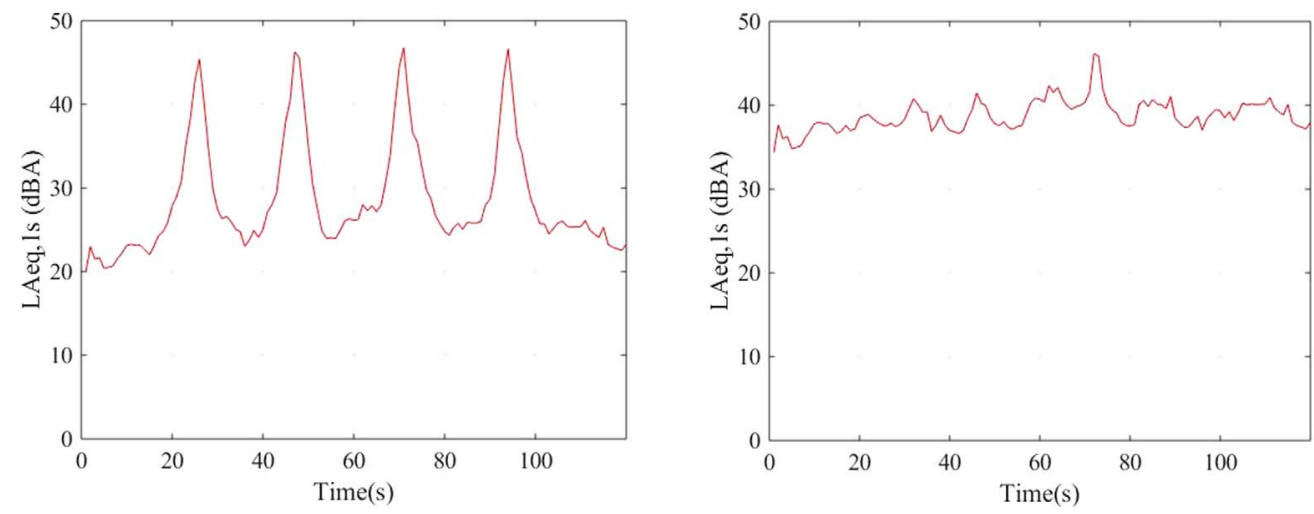

Figure 2. Training session sequences: $L_{\mathrm{Aeq}}$, 1s for the sound sequence with 4 peaks of an emergence of $24 \mathrm{~dB}(\mathrm{~A})$ on the left and $L_{\mathrm{Aeq}}$, $1 \mathrm{~s}$ for the sound sequence with 1 peak of an emergence of $9 \mathrm{~dB}(\mathrm{~A})$ on the right.

- The first question consisted of the recognition of a target word. It might be said whether it was French or not. Non-French words were invented words. All French target words had a contextual proximity with the text.

- The second question was a question of comprehension on the text that had just been read. The participant had to decide whether the statement he was reading was true or false.

The reading part of the experiment was originally designed to evaluate the reading and comprehension skills of 10-year-old children. When the text is well understood, the reader produces inference during the reading which causes a pre-activation of the semantic field of the target word. The speed of correct answers for the target word depends on the reading fluency [30]. As this pre-activation is supposed to be automatic for an adult reader, and therefore without cognitive effort, the speed of response to the target words has not been studied in this research. In contrast, assuming that the noise of events may influence the cognitive load of the reader, the time for reading a line and the performance on text comprehension have been studied as indirect measures of noise disturbance. Table 3 presents an example of the process for one text and its associated questions. A first fixed waiting period $\mathrm{W}_{1}$ $(1500 \mathrm{~ms})$ gave the participant time to be ready for the task, then the participant read the six lines and waited again $500 \mathrm{~ms}\left(\mathrm{~W}_{2}\right)$ in order to focus on the position of the word that will appear in the middle of the screen, before answering the questions. If a participant was a fast reader doing this process with less than $30 \mathrm{~s}$, an additional waiting period $\mathrm{W}_{3}$ was added in order to spread out the four texts over the $2 \mathrm{~min}$. If a participant was a slow reader doing the process with more than $30 \mathrm{~s}$, no additional waiting period was added and the $\mathrm{W}_{1}$ waiting period started immediately with the stars on the screen.

Finally, after each sound sequence, participants had to rate in silence the reading disturbance with this specific wording: "Globalement, l'ambiance sonore dans laquelle vous venez d'être plongé(e) était-elle plus ou moins gênante 
Table 3. Steps of the process for one text and its associated questions as an example.

\begin{tabular}{|c|c|c|c|c|}
\hline Code & Step & Display & Translation & Answering key \\
\hline $\mathrm{W}_{1}$ & $\begin{array}{l}1500 \mathrm{~ms} \text { of waiting period } \mathrm{W}_{1} \\
\text { forcing the eyes to fix the stars }\end{array}$ & $* * *$ & $* * *$ & - \\
\hline $\mathrm{R}$ & Line/Page $n^{\circ} 1$ & $\begin{array}{l}\text { "La nuit est tombée sur le } \\
\text { laboratoire de biologie }\end{array}$ & $\begin{array}{l}\text { "Night has fallen on the } \\
\text { biology laboratory }\end{array}$ & next \\
\hline $\mathrm{R}$ & Line/Page $\mathrm{n}^{\circ} 2$ & $\begin{array}{c}\text { Cependant, une lumière est } \\
\text { restée allumée au }\end{array}$ & $\begin{array}{l}\text { However, a light remained on } \\
\text { in the }\end{array}$ & next \\
\hline $\mathrm{R}$ & Line/Page $n^{\circ} 3$ & $\begin{array}{c}\text { dernier étage de l'immeuble } \\
\text { où sommeillent les }\end{array}$ & $\begin{array}{l}\text { the top floor of the building, } \\
\text { where sleep the }\end{array}$ & next \\
\hline $\mathrm{R}$ & Line/Page $n^{\circ} 4$ & $\begin{array}{l}\text { petits animaux dans leur } \\
\text { cage. C'est alors qu'un }\end{array}$ & $\begin{array}{l}\text { small animals in their cage. It } \\
\text { is then that a }\end{array}$ & next \\
\hline $\mathrm{R}$ & Line/Page $\mathrm{n}^{\circ} 5$ & $\begin{array}{c}\text { homme vêtu de noir entre } \\
\text { silencieusement. }\end{array}$ & $\begin{array}{c}\text { man dressed in black enters } \\
\text { silently. }\end{array}$ & next \\
\hline $\mathrm{R}$ & Line/Page $n^{\circ} 6$ & $\begin{array}{c}\text { Il éteint toutes les lumières du } \\
\text { laboratoire. }\end{array}$ & $\begin{array}{c}\text { It turns off all the lights in } \\
\text { the laboratory." }\end{array}$ & next \\
\hline $\mathrm{ACQ}$ & Comprehension question & $\begin{array}{c}\text { L'homme n'a probablement } \\
\text { pas le droit d'être là. }\end{array}$ & $\begin{array}{l}\text { The man probably has no } \\
\text { right to be there. }\end{array}$ & True \\
\hline $\mathrm{W}_{3}$ & $\begin{array}{l}\text { Variable waiting time } \mathrm{W}_{3} \text { in } \\
\text { order to avoid the all process } \\
\text { to be less than } 30 \mathrm{~s}\end{array}$ & $* * *$ & $* * *$ & - \\
\hline
\end{tabular}

pour la lecture? Voici un curseur d'opinion gradué de 0 à 10. Notez 0 (à gauche) si le bruit ne vous a pas gêné du tout et notez 10 (à droite) si le bruit vous a extrêmement gêné. Si vous êtes entre ces deux situations, choisissez une note intermédiaire entre 0 et 10" ("Overall, was the sound environment in which you have just been immersed more or less disturbing for reading? Here is an opinion cursor graduated from 0 to 10 . Rate 0 (on the left) if the noise did not disturb you at all and rate 10 if the noise extremely disturbed you. If you are between these two situations, choose a score between 0 and 10"). After having validated their rating, another sound sequence started, triggered randomly among the remaining other sound sequences. Again, participants had to wait $1500 \mathrm{~ms}$, fixing three stars on the screen and preparing their fingers on the keyboard, before reading another text. The all test lasted about $1 \mathrm{~h} 30$ and consisted of the following steps:

- Written information on the study and the test.

- Audiogram to check the correct hearing of the participant.

- Written participant consent.

- Training session with two extreme sound sequences (Fig. 2).

- Test per se: participants were exposed to 16 sound sequences while reading.

- End of the test with debriefing.

- Filling out a receipt of gratification.

The participants were informed about this study via written information with a welcome sheet where various instructions were given, such as the position to hold for the participant during the test. The laptop had to be on the knees, the back well installed in the armchair, the fingers on the keyboard (one key for "true", one key for "false" and one key for "next", see Tab. 3).

The interface was developed on OpenSesame ${ }^{3}$, a software designed for psychological tests that records all the participants' answers in the form of variables. The texts, previously designed for psychological tests with children, are calibrated for both size and reading difficulty [31]. This calibration ensures that overall variations in reading times are not due to the content of the texts. The OpenSesame interface was then synchronized with the Max $/ \mathrm{MSP}^{4}$ sound broadcasting software using the OSC communication protocol.

\subsection{Participants}

A communication campaign was carried out within $\mathrm{CY}$ Cergy Paris University to recruit French native language participants. The recruitment criterion was noise sensitivity, which was evaluated via an online questionnaire $[32,33]$. Questions concerned usual reactions to noises that people encounter in their everyday life. Candidates had to rate their agreement with sentences about noise on a Likert scale ("I totally agree", "I rather agree", "I rather disagree" or "I totally disagree"). Scores of sensitivity varied from 0 to 3. Among interested people, 14 participants were selected with a sensitivity score under 1.7 and were clustered in the non-sensitive group, 15 participants were selected with a sensitivity score above 1.7 and were clustered in the noise sensitive group. Among the 29 participants, 19 were female

\footnotetext{
3 https://osdoc.cogsci.nl/2.9.2/getting-opensesame/

${ }^{4}$ https://cycling74.com/get-started
} 


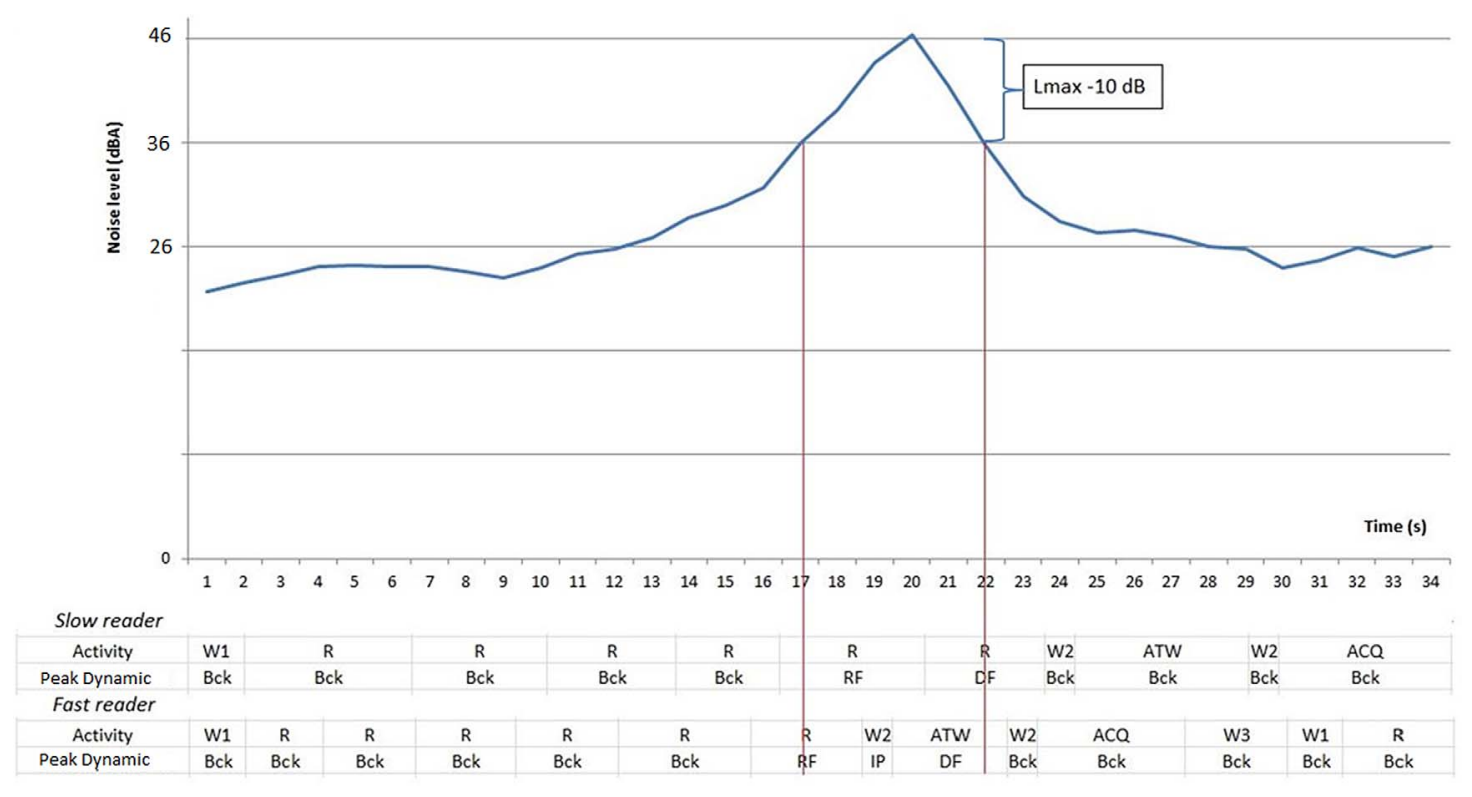

Figure 3. Application of the synchronization algorithm for a fast reader and a slow reader.

and 10 were male, they were all students aged from 18 to 28 with a median value of 21 . They received a gratification of $20 €$ for their duties.

\subsection{Calculation of the reading times}

Data were processed to reconstruct the reading and the sound timelines of the participants during the progress of their test. Concerning the reading timeline, four categories of activities performed by the participants have been identified: Reading (R), Waiting (W), Answering the TargetWord (ATW), Answering the Comprehension Question (ACQ). The time limits of each type of activity correspond to the instants when participants select an answering key and the duration of this activity is the difference between these two instants. Then, all participants followed the activities at their own speed for each text, with the following time steps: $\mathrm{W}_{1}-\mathrm{R}-\mathrm{R}-\mathrm{R}-\mathrm{R}-\mathrm{R}-\mathrm{R}-\mathrm{W}_{2}-\mathrm{ATW}-\mathrm{W}_{2}-\mathrm{ACQ}-\mathrm{W}_{3}$ (Tab. 3).

Concerning the sound timeline, the evolution of the sound level during the test has been divided into five dynamic categories: silence corresponding to the background noise of the laboratory without any sound sequence (Sil), background noise of a sound sequence when there is no emerging event (Bck), rising front of a peak $(\mathrm{RF})$, installed peak (IP) and descending front of a peak (DF). As a pass-by event is defined when the sound level is above $L_{\mathrm{Amax}}-$ $10 \mathrm{~dB}(\mathrm{~A})$, a specific Matlab routine has been developed in order to allocate the different activities (and especially the reading task) to the different clusters of peak dynamic: (1) The rising front of the peak $(\mathrm{RF})$ is defined as the first time step when the noise levels exceed $L_{\mathrm{Amax}}-10 \mathrm{~dB}(\mathrm{~A})$ for at least $50 \%$ of an activity duration; (2) The next following time steps are counted as Installed peak (IP) as long as the noise levels exceed $L_{\mathrm{Amax}}-10 \mathrm{~dB}(\mathrm{~A})$ for $100 \%$ of an activity duration; (3) The first time step not counted as
IP is counted as descending front of the peak (DF) if noise levels exceed $L_{\mathrm{Amax}}-10 \mathrm{~dB}(\mathrm{~A})$ for at least $50 \%$ of an activity duration; (4) All the time steps that are not clustered in the three previous categories are associated to the background noise (Bck), except if at least $50 \%$ of an activity duration is realized after the end of a sound sequence. In that case, these time steps are associated to silence (Sil). Actually, if readers are very slow, it may happen that the test lasts more than 2 min and some lines of the last text are read in silence.

The algorithm is illustrated in Figure 3 for both a fast and a slow reader. It shows that the synchronisation depends on each participant. For example, for slow readers, it is possible that no read line would be allocated to the IP category because the reading activity in the rising front would be too long. In that case, the following line after the $(\mathrm{RF})$ category is allocated to (DF)) or even to (Bck) if the reading activity is very long.

\subsection{Calculation of the reading time change}

It could be interesting to measure individually the importance of the change in the reading time between two categories of peak dynamic (for example between the reading time during the rising front noise, and the reading time during the background noise). The percentage of change is calculated for each participant, and for each sequence as follows:

\section{See the Equation (1) top of next page}

It represents a relative slowdown in reading speed if the $\%$ of change is positive (for example if the reading time is longer during the rising front compared to the reading time during the background noise), and a relative acceleration if the $\%$ of change is negative. 
$\%$ of Change $=\frac{\text { Median reading time during cat } \cdot \mathrm{A}-\text { Median reading time during cat } \cdot \mathrm{B}}{\text { Median reading time during cat } \cdot \mathrm{B}}$.

\subsection{Statistical analysis}

The strong variability in the reading time per line among the participants and among the sequences made the distribution of the data incompatible with a classical ANOVA (no equality of variances neither Gaussian distribution). So non-parametric tests were used in this paper for the analysis of the reading time per line. Kruskal-Wallis tests [34] were chosen to study the differences between median ranks and Wilcoxon tests were chosen for posthoc analyses [35] when data were disaggregated between participants. When a repeated measure design could be used, Friedman tests [36] and Nemenyi post-hoc analysis [37] were chosen.

For the reading disturbance whose data followed a repeated measure design, multi-level models [38] were also used to explain variability of this specific dependant variable and to study relationships with independent variables, if assumptions were respected.

In this paper, four $p$-value thresholds are considered: $p<0.001, p<0.01, p<0.05$ for significance and $p<0.1$ for tendency.

\section{Results}

\subsection{Distribution of data}

\subsubsection{Statistics on participants}

Figure 3 shows that the reading speed of participants could have an impact on the distribution of the data. So, participants have been clustered as fast and slow readers, respectively below and above the median value of their mean reading time per line which is $2513 \mathrm{~ms} /$ line (1619 ms/line and $4563 \mathrm{~ms} /$ line respectively for the quicker reader and for the slowest reader). Consequently, the reading speed groups are fairly balanced (14 fast readers and 15 slow readers). There is no correlation between noise sensitivity and the reading speed in this corpus (Pearson $r=0.068, p=0.72$ ). This will make it possible to look at the influence of these two characteristics separately if necessary.

\subsubsection{Statistics on reading time per line}

With a total of 11136 read text lines, Table 4 presents the number of these lines inside each peak dynamic category and the corresponding medians of the reading time per line for all participants.

Two categories (IP) and (Sil) cannot be compared to the others for different reasons:

- With such a short car pass-by duration (4800 ms when the sound pressure levels exceed $\left.L_{\mathrm{Amax}}-10 \mathrm{~dB}(\mathrm{~A})\right)$,
Table 4. Number of text lines read in each peak dynamic category for the 16 sound sequences and medians of reading time per line, all participants included.

\begin{tabular}{lccccc}
\hline Sequence & $(\mathrm{Bck})$ & $(\mathrm{RF})$ & $(\mathrm{IP})$ & $(\mathrm{DF})$ & $(\mathrm{Sil})$ \\
\hline 1 & 635 & 25 & 5 & 14 & 17 \\
2 & 607 & 36 & 11 & 21 & 21 \\
3 & 634 & 11 & 8 & 15 & 28 \\
4 & 567 & 53 & 17 & 39 & 20 \\
5 & 631 & 19 & 1 & 10 & 35 \\
6 & 620 & 36 & 2 & 6 & 32 \\
7 & 628 & 33 & 0 & 17 & 18 \\
8 & 607 & 51 & 2 & 20 & 16 \\
9 & 611 & 22 & 12 & 16 & 35 \\
10 & 604 & 38 & 15 & 21 & 18 \\
11 & 599 & 32 & 9 & 35 & 21 \\
12 & 544 & 64 & 27 & 32 & 29 \\
13 & 616 & 22 & 11 & 18 & 29 \\
14 & 606 & 36 & 14 & 19 & 21 \\
15 & 602 & 32 & 9 & 33 & 20 \\
16 & 576 & 53 & 17 & 29 & 21 \\
Total & 9687 & 563 & 160 & 345 & 381 \\
Median value in ms/line & 2222 & 2466 & 1674 & 2225 & 3322 \\
\hline
\end{tabular}

there is a limitation of the (IP) duration. For the faster reader where $50 \%$ of his/her mean reading time $(1619 \mathrm{~ms} /$ line $)$ is on the rising front (about $800 \mathrm{~ms}$ ) and $50 \%$ of the same reading time on the descending front (about $800 \mathrm{~ms}$ ), the maximum duration of an (IP) slot is about $3200 \mathrm{~ms}(4800-2 \times 800)$. This means that for all the other participants, the maximum duration of an (IP) reading time for a line is smaller than $3200 \mathrm{~ms}$. In contrast, there is no limitation of the reading time duration for the background category. For the (RF) and (DF) categories, as the noise levels should exceed $L_{\mathrm{Amax}}-10 \mathrm{~dB}(\mathrm{~A})$ for at least $50 \%$ of the reading duration, the maximum duration for these two categories is twice the event duration which corresponds to $9600 \mathrm{~ms}(2 \times 4800)$. This limitation due to the routine is not a limitation for readers, as the mean reading time for the slowest reader is $4563 \mathrm{~ms} /$ line. Moreover, there are 132 (IP) observations for fast readers and only 28 (IP) observations for slow readers, leading to an underestimation of the reading time during (IP).

- With the chosen protocol, all the lines that are read in silence are read after the end of the sound sequences. All the lines, whose reading times are allocated to the other categories (Bck) (RF) (IP) and (DF), are read during the 2-min sequences. Consequently, 350 lines are read in silence (Sil) by slow readers and only 31 (Sil) lines are read in silence by fast readers, leading to an overestimation of the reading time during silence (Sil). 


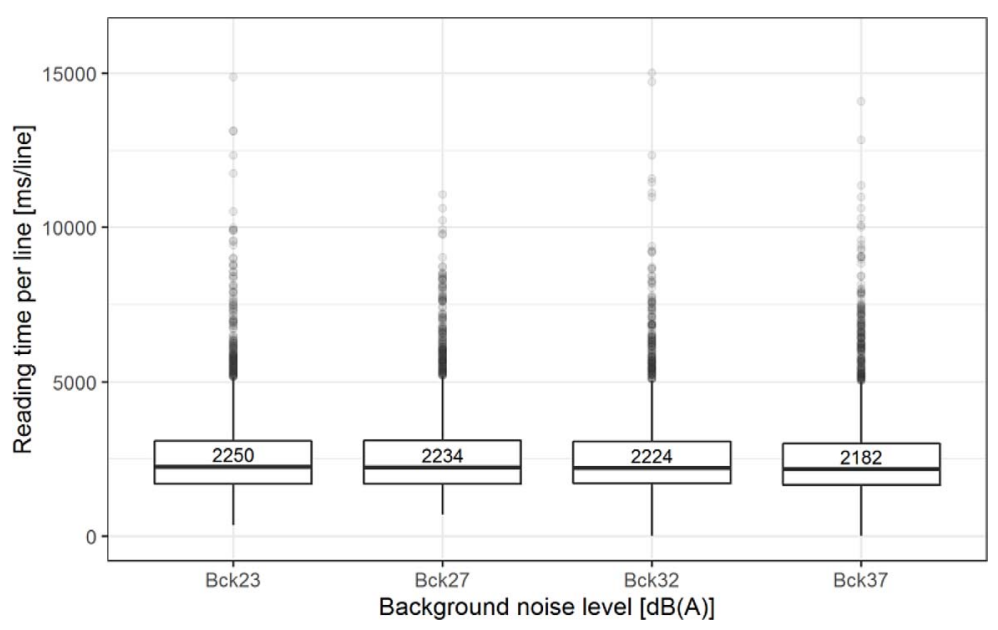

Figure 4. Distribution of the reading time per line for background categories with median values.

So, in the following sections, the two categories (IP) and (Sil) will not be compared to the three others (Bck), (RF) and (DF). The corresponding data are then excluded from the statistical analysis.

\subsection{Reading time per line}

\subsubsection{Influence of a stable background sound level}

A prior investigation consists in studying the reading time per line depending on the sound level. The experiment design allows to study the distribution of these times among the four background noises (Fig. 4), which vary from about $23 \mathrm{~dB}(\mathrm{~A})$ for sequences $13-16$, to about $37 \mathrm{~dB}(\mathrm{~A})$ for sequences 1-4 (see Tab. 1). There is no significant difference between the median reading times during the background period (Kruskal-Wallis $p$-value $=0.078$ ). This means that continuous and stable low sound levels do not influence the reading speed of participants.

Of course, there is a significant difference in reading time per line in the background noise of the sequences between fast and slow readers (Kruskal-Wallis $p$-value $<0.001$ ) with a median value equals to $1898 \mathrm{~ms} /$ line for fast readers and $2655 \mathrm{~ms} /$ line respectively for slow readers. It is also the case between sensitive and non-sensitive participants (KruskalWallis $p$-value $<0.001$ ) with a median value of $2294 \mathrm{~ms}$ /line for sensitive participants and $2160 \mathrm{~ms} /$ line for non-sensitive participants.

\subsubsection{Influence of the line rank order}

Another investigation is carried out to evaluate the impact of the line rank order on the reading time per line in a text. A Kruskal-Wallis test shows that the line rank order has a highly significant effect on the reading time per line $(p<0.001)$. Three groups $\mathrm{a}, \mathrm{b}$ and $\mathrm{c}$ representing significant different distributions are extracted from the Wilcoxon post-hoc analysis. Figure 5 shows that the median reading time is higher for the first line of a text compared to any other lines.
This delay could be explained by the fact that people have to start again a cycle, changing their attention from answering question on a text to concentrating on reading a new text and forgetting the previous one. They have to build the bases of understanding a new story by taking the first information [39]. They also maybe need time to check the fingers are correctly placed on the keyboard although the waiting time $\mathrm{W} 1$ of $1500 \mathrm{~ms}$ should be enough for that. This effect decreases as the text goes on, and there is no difference anymore in the reading time for the three last lines.

\subsubsection{Influence of the peak dynamic category}

As the distribution of the first line over the peak dynamic categories is similar to the distribution of the other lines (Tab. 5), the first line is kept all over the following analyses.

The Kruskal-Wallis test shows that the peak dynamic category has a highly significant influence on the reading time per line $(p<0.001)$. Two groups a and $\mathrm{b}$ representing significant different distributions are extracted from the Wilcoxon post-hoc analysis (Fig. 6). Differences of medians are significant between $(\mathrm{RF})$ and $(\mathrm{Bck})(<0.001)$ as well as between $(\mathrm{RF})$ and $(\mathrm{DF})(<0.001)$, but there is no difference between (Bck) and (DF) $(p=0.755)$.

This peak dynamic factor is not significant for fast readers (Kruskal-Wallis $p$-value $=0.051$ ). It is only significant for slow readers $(p<0.001)$, with a significant increase in the reading time (Wilcoxon post-hoc $p$-value $<0.001$ ) between the background noise $\left(M_{\mathrm{Bck}}=2655 \mathrm{~ms} /\right.$ line $)$ and the rising front $\left(M_{\mathrm{RF}}=3102 \mathrm{~ms} /\right.$ line $)$. The dynamic of the peak factor is significant for both sensitive and nonsensitive groups $(p<0.001$ for sensitive participants as well as for non-sensitive ones).

This peak dynamic factor is not significant for fast readers (Kruskal-Wallis $p$-value $=0.051$ ). It is only significant for slow readers $(p<0.001)$, with a significant increase in the reading time (Wilcoxon post-hoc $p$-value $<0.001$ ) between the background noise $\left(M_{\mathrm{Bck}}=2655 \mathrm{~ms} /\right.$ line $)$ and the rising front $\left(M_{\mathrm{RF}}=3102 \mathrm{~ms} / \mathrm{line}\right)$. The dynamic of 


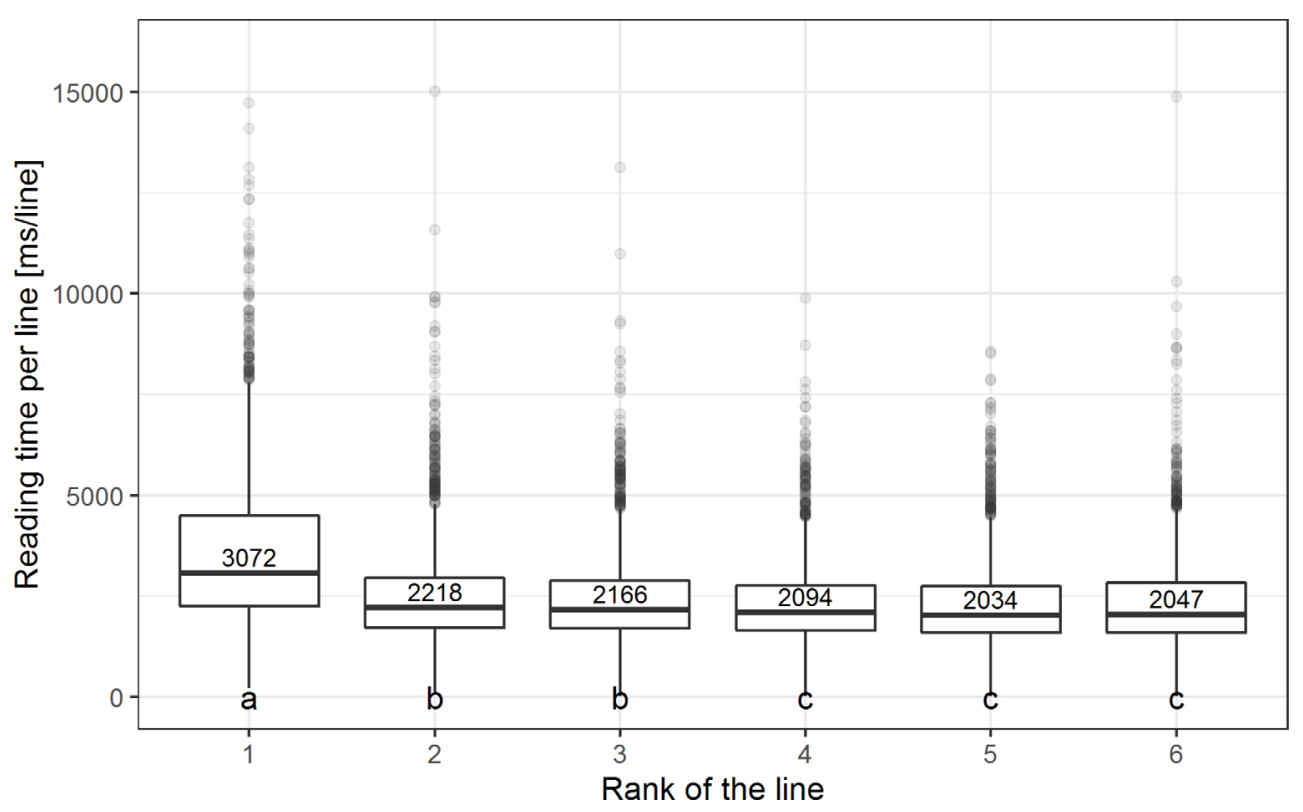

Figure 5. Distribution of the reading time per line according to the line rank order, with median values. Three groups a, b and c representing significant different distributions are extracted from the Wilcoxon post-hoc analysis.

Table 5. Number of text lines read for each rank of line for the 16 sound sequences, all participants included.

\begin{tabular}{lccc}
\hline Line rank order & $(\mathrm{Bck})$ & $(\mathrm{RF})$ & $(\mathrm{DF})$ \\
\hline 1 & 1650 & 91 & 63 \\
2 & 1618 & 125 & 57 \\
3 & 1610 & 106 & 61 \\
4 & 1591 & 92 & 78 \\
5 & 1619 & 67 & 60 \\
6 & 1599 & 82 & 26 \\
Total & 9687 & 563 & 345 \\
\hline
\end{tabular}

the peak factor is significant for both sensitive and nonsensitive groups $(p<0.001$ for sensitive participants as well as for non-sensitive ones).

The individual slowdowns in the reading speed are calculated with Equation (1) in Section 2.6. The global median slowdown equals to $8.8 \%$. Kruskal-Wallis tests reveal that there is a significant difference between fast and slow readers $(p=0.005)$ but no significant difference between sensitive and non-sensitive groups $(p=0.323)$. If the median slowdown is limited to $4 \%$ with fast readers, it goes up to $14 \%$ for slow readers.

\subsection{Reading disturbance}

\subsubsection{Influence of personal factors}

The median of the reading disturbance values increases significantly from 1.1 for fast readers to 3.0 for slow readers (Kruskal-Wallis test $p$-value $<0.001$ ). Similarly, an increase of the reading disturbance values is observed from 1.3 for non-sensitive participants to 2.8 for sensitive ones $(p$ value $<0.001)$. It has to be noted that the disturbance ratings are very low, compared to the 11-point scale.

\subsubsection{Influence of the sound sequence factors}

It is possible to analyse the disturbance data with a repeated measure design for each couple of groups. The dependent variable is the reading disturbance, and the independent variables are the (BoE) factor (4 levels) and the (NoP) factor (4 levels too, see Tab. 1).

- The number of peaks (NoP) does not influence the reading disturbance (Friedman $p$-value $=0.506$ ). The same result is also observed if the analysis is carried out on each couple of groups.

- The (BoE) factor is significant (Friedman $p$-value $=$ 0.005 ). If the analysis is carried out on the sensitivity groups, this effect is only significant for sensitive people $(p=0.011$, respectively $p=0.233$ for non-sensitive participants), with an increase of disturbance following the increase of background noise. Two groups of sequences $\mathrm{a}, \mathrm{b}$ representing significant different distributions are extracted from the Nemenyi post-hoc analysis. It shows that the sound sequences with a higher background noise of $37 \mathrm{~dB}(\mathrm{~A})$ and lower emergence of $9 \mathrm{~dB}(\mathrm{~A})$ (stimuli 1 to 4 altogether) are significantly different from the others $(p=0.028, p=0.028, p=0.042$ respectively for Bck23_Em24, Bck27_Em19, Bck32 Em14) and are considered as more disturbing than the others for the reading task (Fig. 7).

If the analysis is carried out on the reading fluency groups, the (BoE) factor has a significant impact on reading disturbance for fast readers (Friedman $p$-value $=0.027)$ but not for slow readers $(p=0.224)$, with sequences $1-4$ altogether (Bck37 Em9) different from sequences with Bck23_Em24 (Nemenyi post-hoc $p$-value $=0.036)($ Fig. 8$)$.

This influence of the $(\mathrm{BoE})$ factor is only revealed for noise sensitive participants and for fast readers, although 


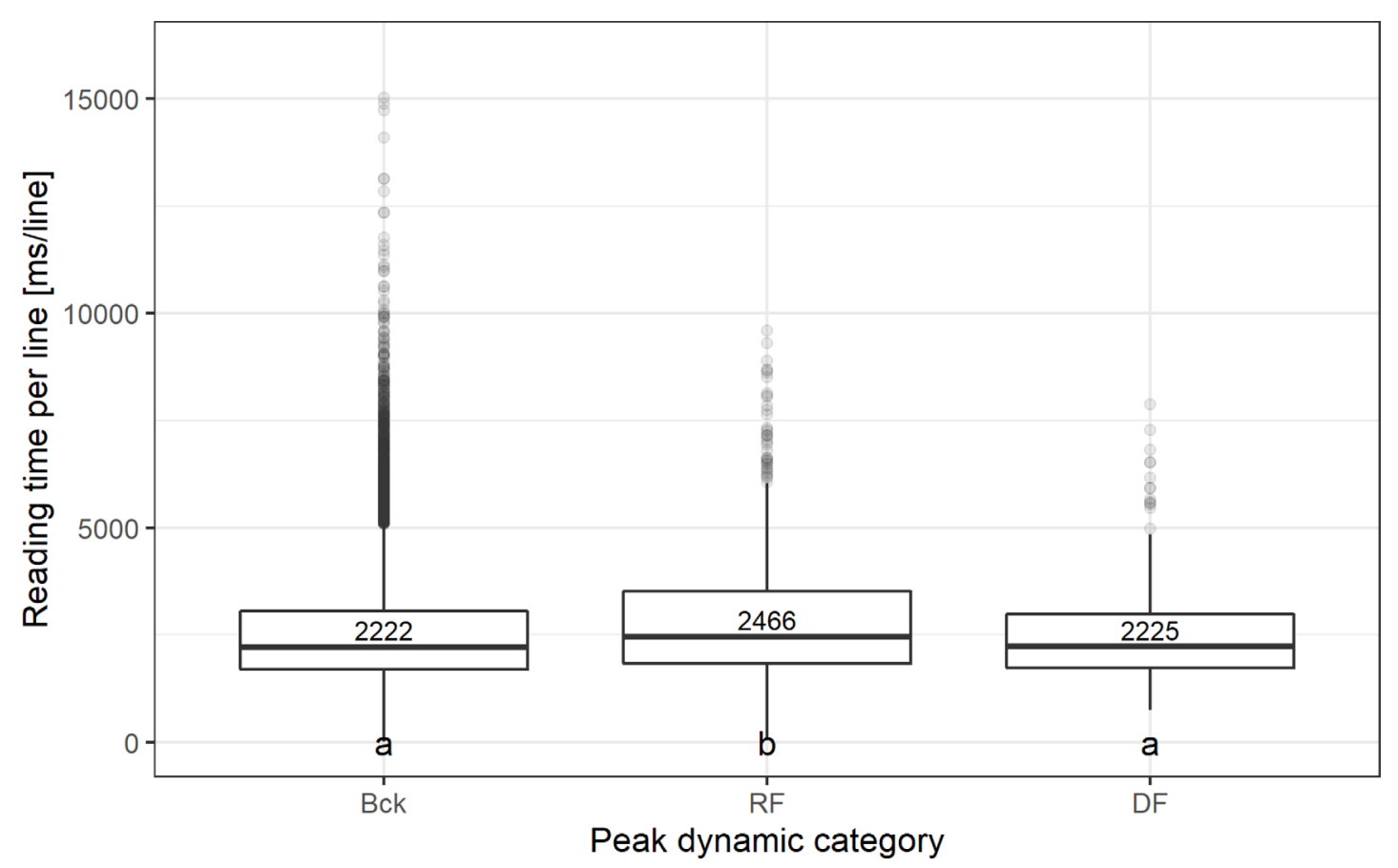

Figure 6. Distribution of the reading time per line according to the peak dynamic category, with median values. Two groups a and b representing significant different distributions are extracted from the Wilcoxon post-hoc analysis.

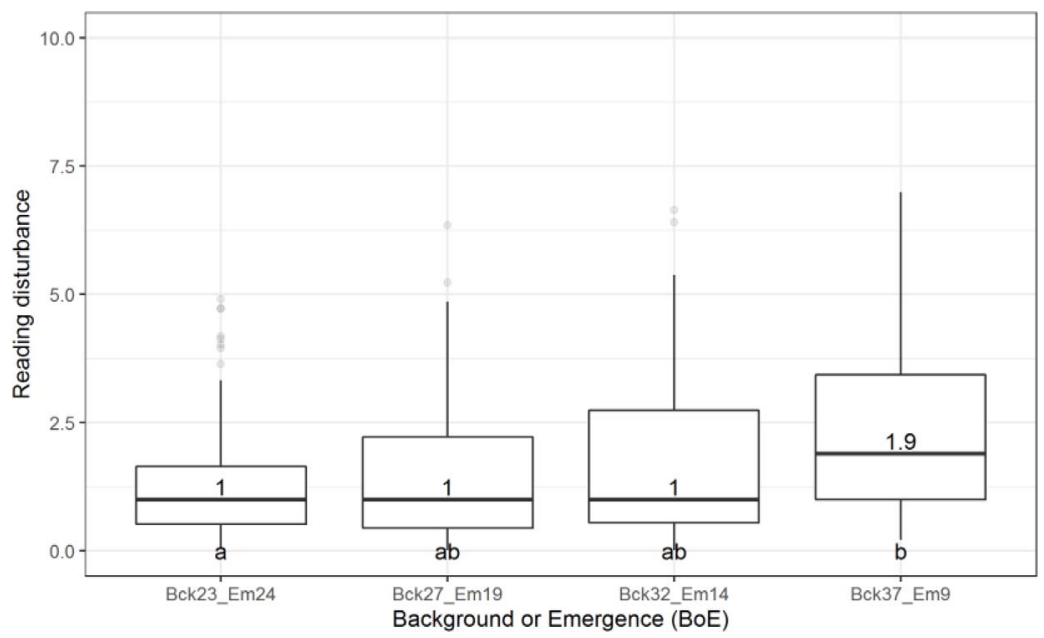

Figure 7. Reading disturbance according to the (BoE) factor only for the group of noise sensitive participants. Labels correspond to median values for each distribution. The two groups a and b, representing significant different distributions, are extracted from the Nemenyi post-hoc analysis.

slow readers are more disturbed than fast readers. This not intuitive result will be discussed in Section 4.2.

\subsubsection{Reading disturbance explained by personal and sound sequence factors}

Multi-level analyses were carried out to explain and quantify the variance of the reading disturbance data (Tab. 5) at the individual and at the sound sequence levels using the package "lme4" of the $R$ statistical software [40]. Personal data were included in the models as fixed continuous factors, taking the scores of the preliminary questionnaire (Sect. 2.4) for noise sensitivity and taking the mean reading time per line (Sect. 3.1.1) for the reading slowness. Sound sequence parameters correspond to the acoustic indicators $L_{90}, L_{\text {Aeq }}$ and Emergence (Tab. 1) and the (NoP) factor. In order to respect the assumption of normal distribution of the residuals, two participants were excluded from this analysis. They do not react as the others for the reading disturbance, rating all the sound sequences with constant assessments (around "1") although they are the two slowest readers. 


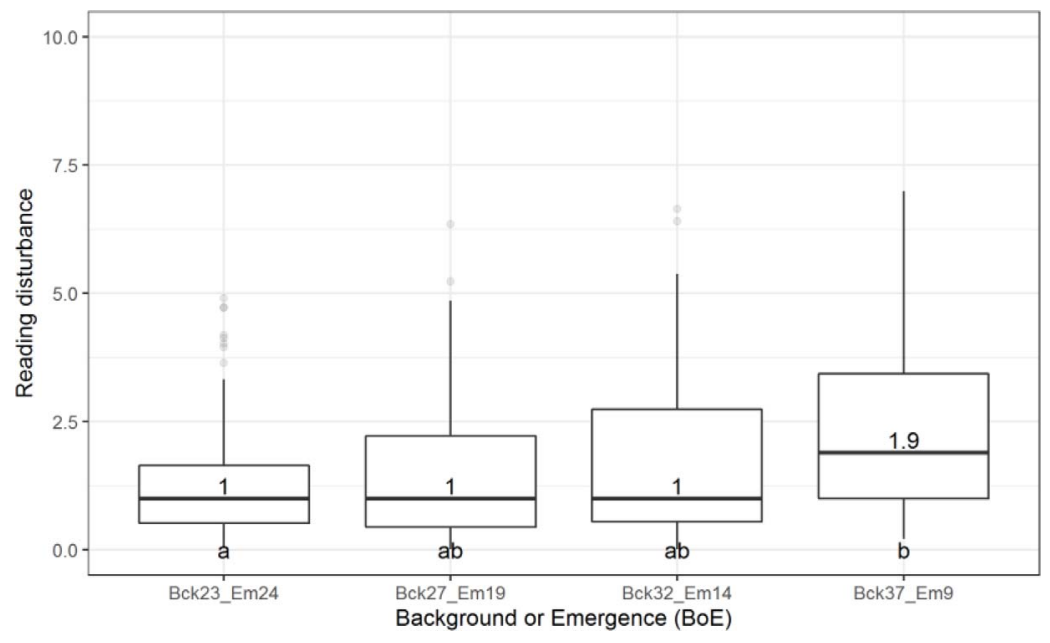

Figure 8. Reading disturbance according to the (BoE) factor only for the fast reader group. Labels correspond to median values for each distribution. The two groups a and b, representing significant different distributions, are extracted from the Nemenyi post-hoc analysis.

Table 6. Multi-level models of reading disturbance with regression coefficients (standard errors, $t$-value) for fixed part and with variance components (standard error) for random part. Significance of estimates is noted $* * *(p<0.001)$, ${ }^{* *}(p<0.01)$ or $*(p<0.05)$.

\begin{tabular}{|c|c|c|c|c|}
\hline $\begin{array}{l}\text { Models } \\
\text { Fixed part }\end{array}$ & Null Model & Model 1 & Model 2 & Best Model \\
\hline Intercept & \multirow[t]{4}{*}{$2.79(0.43 ; 6.53)^{* * *}$} & \multirow[t]{3}{*}{$-2.05(0.86 ;-2.39)^{*}$} & $-6.41(1.56 ;-4.12)^{* * *}$ & $-1.13(1.73 ;-6.52)^{* * *}$ \\
\hline Sensitivity & & & $1.56(0.46 ; 3.39)^{* *}$ & $1.56(0.461 ; 3.39)^{* *}$ \\
\hline Reading slowness & & & $2.6 \mathrm{e}-03(5.48 \mathrm{e}-04 ; 4.69)^{* * *}$ & $2.57 \mathrm{e}-03(5.48 \mathrm{e}-4 ; 4.67)^{* * *}$ \\
\hline$L_{\text {Aeq }}$ & & $0.13(0.021 ; 6.46)^{* * *}$ & & $1.33 \mathrm{e}-01(2.06 \mathrm{e}-02 ; 6.46)^{* * *}$ \\
\hline Pseudo $R$ fixed effects & 0 & 0.02 & 0.44 & 0.46 \\
\hline Sound sequences & $0.13(0.36)$ & $0.00(0.00)$ & $0.13(0.36)$ & $0.00(0.00)$ \\
\hline Residual & $1.42(1.19)$ & $1.41(1.19)$ & $1.42(1.19)$ & $1.41(1.19)$ \\
\hline Goodnesss of fit & & & & \\
\hline $\mathrm{AIC}$ & 1510.5 & 1495.9 & 1503.3 & 1488.7 \\
\hline $\mathrm{BIC}$ & 1526.8 & 1516.23 & 1527.7 & 1517.2 \\
\hline
\end{tabular}

The global variance of the "Null model" is 6.15. The multi-level analysis shows that the variance due to the participants is 4.60 which represents $75 \%$ of the global variance. The variance due to a change of the sound sequence represents only $2 \%$ of the global variance. Finally, $33 \%$ of the total variance cannot be explained by any of these random parameters. If we introduce in the models the acoustic indicators as fixed effects, the best model is obtained with $L_{\text {Aeq }}$ (Model 1$)$. It reduces the random part of the global variance $(6.15-6.01=0.14)$ of $2 \%$ $(0.14 / 6.15)$. If both personal factors are included as fixed effects in the Model 2, the fixed part explains $44 \%$ of the total variance because it reduces the random part of the global variance $(6.15-3.47=2.68)$ of $44 \%(6.68 / 6.15)$. Globally, the fixed part of the final best Model with the two personal factors and the $L_{\text {Aeq }}$ explains $46 \%$ of the total variance. It is interesting to note that the acoustic indicator $L_{\text {Aeq }}$ (Model 1) explains $100 \%$ of the variance at the sound sequence level $(0.13-0.00 / 0.13=100 \%)$ and that the two personal factors (Model 2) explain $58 \%$ of the variance at the participant level $(4.60-1.92 / 4.60=58 \%)$ (Tab. 6).

\subsection{Comprehension rate}

For each sound sequence, the comprehension rate of a participant is the percentage of good answers at the comprehension question. As there are four texts during each sound sequence, the comprehension rate takes only five values that are $1,0.75,0.5,0.25$ and 0 . Normal distribution is not assumed either for the data nor for residuals so nonparametric tests are used again. There is no significant difference between speed reading groups (Kruskal-Wallis $p$-value $=0.117)$ neither between noise sensitivity groups (Kruskal-Wallis $p$-value $=0.873$ ) for the comprehension rate. All participants succeeded quite well to the exercise whatever their personal factors. It must be remembered that the cognitive test has been initially designed for 10-year-old children. All participants are then included together in a non-parametric repeated measure design. 


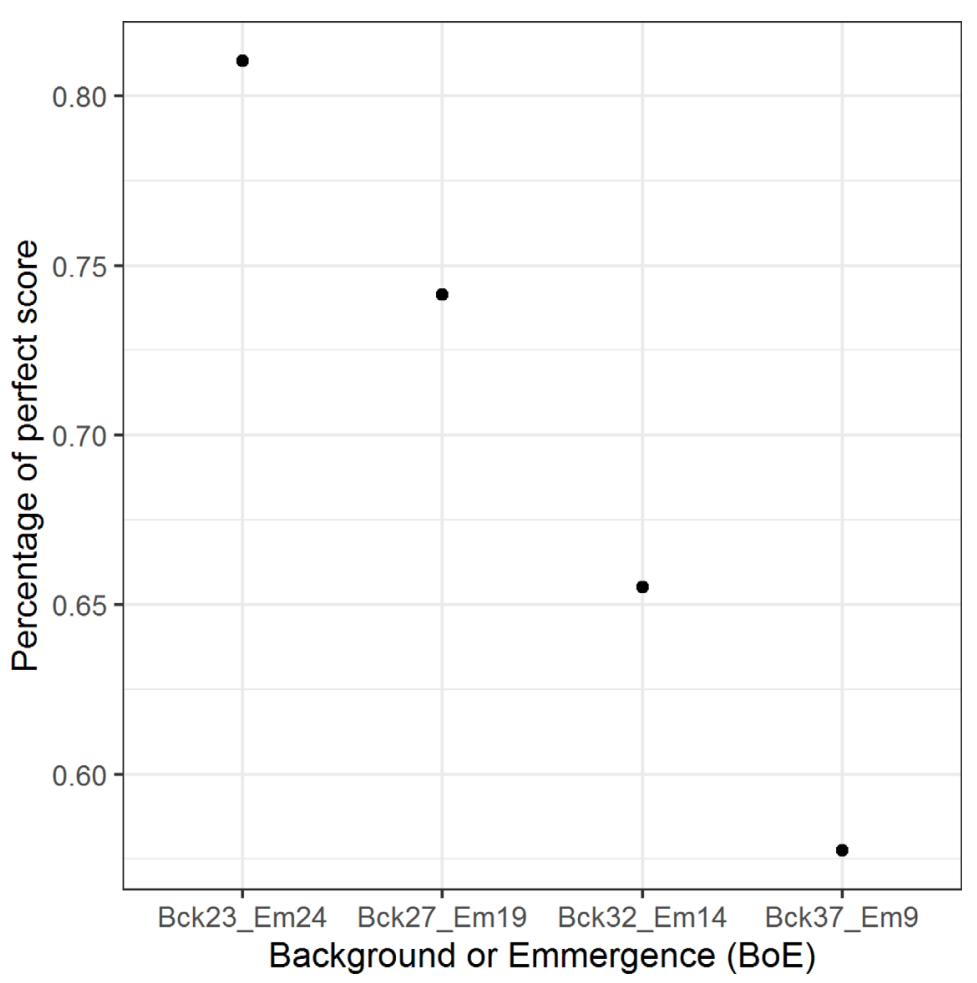

Figure 9. Influence of the (BoE) factor on the percentage of perfect scores.

The (NoP) factor has no influence of the comprehension rate, and there is no significant difference between any pairs of sequences. On the contrary, the (BoE) factor has a significant influence on the comprehension rate (Friedman $p$-value $<0.001)$ with a decrease of the comprehension rate following the increase of the background noise.

Another way to represent this effect is to calculate for each category, the ratio of perfect ratings that correspond to 4 good answers at the four comprehension questions (Fig. 9). For example, for the sound sequences 13-16, there are $29 \times 4$ observations (4 stimuli and 29 participants). Among these 116 observations, only 94 reached 1 as comprehension rate. The ratio of perfect answers is then equal to 0.81 .

\section{Discussion}

\subsection{Synthesis}

A laboratory experiment has been carried out in order to reveal the influence of fluctuating road traffic noise on the disturbance perceived by participants during an easy reading task as well as their performance, inside a living room with closed windows. Sixteen 2-min sound sequences were created with one to four noise peaks with an emergence varying from 9 to $24 \mathrm{~dB}(\mathrm{~A})$ with a $5 \mathrm{~dB}(\mathrm{~A})$ step, keeping the maximum sound level constant for each noise event. The consequence of such a design is that all passbys can be considered as quite similar, but the global sound level varies from $31 \mathrm{~dB}(\mathrm{~A})$ to $41 \mathrm{~dB}(\mathrm{~A})$, and the background sound level varies from $23 \mathrm{~dB}(\mathrm{~A})$ to $37 \mathrm{~dB}(\mathrm{~A})$.
The joint influence of the acoustical characteristics of the sound sequences and personal factors, such as noise sensitivity and speed-reading ability, have been studied on cognitive performance as well as on reading disturbance. The main results can be summarized:

- The reading speed decreases during the rising front of a peak, and goes back to its former regular reading speed during the descending front of the peak.

- The slowdown in reading due to the rising front of a noise peak is increased for participants that are slow readers.

- The comprehension of the text read decreases as the background sound level increases, even if the reading speed does not change with the background sound level.

- Reading disturbance is governed by personal factors, noise sensitive participants declaring higher reading disturbance than non-sensitive ones, as well as slow readers declaring higher disturbance than fast readers.

- Reading disturbance is influenced by the sound pressure levels of the sequences, not by the number of peaks.

- The influence of the sound pressure levels is only revealed for noise sensitive participants and for fast readers.

\subsection{Reading disturbance}

Globally, it can be said that noise sensitive participants and slow readers rated the sequences for reading disturbance in the same range of values around 3. Fast readers 
and non-sensitive participants rated sequences around 1, within a scale range from 0 to 10 . The noise sensitivity factor influenced the reading disturbance. This is in line with literature [41, 42], which demonstrated that sensitive persons are more annoyed than non-sensitive persons by traffic noise in a laboratory context. These ratings show that participants were lightly disturbed for reading because the sound levels are quite low, although they are realistic for a living room with closed double glass window in an urban context. Kurra et al. had similar results on reading disturbance in a laboratory context at such low levels [43]. The ratings of reading disturbance are low also because the activity was easy for adult participants, as it was initially designed for 10-year-old children. It has already been shown that the difficulty of the task is an important factor for the influence of a sound variable on performance [44, 45].

The influence of the (NoP) factor is not revealed in this study. This is not in line with literature for road traffic noise. For example, Gilles et al. [9] found that the increase of the number of vehicles (from 10 to 50 pass-bys for 3-min sequences that corresponds to an increase of 6-30 pass-bys for 2-min sequences) increases the noise annoyance for participants that did not achieve any task but imagined themselves at home while relaxing. In their study, the sound levels varied from 55 to $62 \mathrm{~dB}(\mathrm{~A})$ for open windows. Trollé et al. [46] found also that the increase of the traffic flow (from 20 to 40 pass-bys for 3-min sequences that corresponds to an increase of $13-26$ pass-bys for 2-min sequences) increases the unpleasantness of the sound environment for participants who were asked to imagine themselves outdoor reading at a terrace of a café. In their study, the sound levels varied from 50 to $60 \mathrm{~dB}(\mathrm{~A})$. In this study, participants were involved in a real reading activity, exposed to a smaller number of events and to lower sound pressure levels. This context may explain differences in the results (see also Sect. 4.4 concerning limitations of this study).

This influence of the (BoE) factor is only revealed for noise sensitive participants and for fast readers. This result is not intuitive for fast readers, and could be explained with the reading cognitive processes. In adults, reading requires two types of processes: automatic processes and controlled processes [47]. The controlled processes require significant cognitive effort and attentional resources according to the theory of Schneider and Shiffrin [48]. The performance linked to these processes is then sensitive to disruption. Two kind of readers could then be differentiated. Those with a highly automated reading who could be called "expert" readers, and those with more controlled reading who are less experts [49]. In this perspective, fast readers could be considered as more experts than slow readers. The rising front of the peaks influences the reading speed, especially for slow readers. The rising front must therefore certainly mobilize attentional resources, which can disrupt cognitive activity when it already demands some of the subject's resources. Their reading ability is affected by the rising front of the peak, but their reading disturbance is not influenced by the acoustic factors of the sound sequences. In contrast, the attentional availability of fast readers may explain their increased reading disturbance related to the Bck37_Em9 sound sequences. This availability allows them to be more aware of noise, even if it does not necessarily affect their reading ability during the car pass-bys.

In our study, the only sound sequences which are rated higher than the others on the reading disturbance scale are the loudest ones, whose background noise level reaches $37 \mathrm{~dB}(\mathrm{~A})$, with $9 \mathrm{~dB}(\mathrm{~A})$ of emergence for the events. In buildings or offices, the continuous background noise is generally due to ventilation sounds. Hongisto et al. [50] found that ventilation sounds at about $40 \mathrm{~dB}(\mathrm{~A})$ were rated in the middle of the scale of disturbance for participants who were not working, but were instructed to imagine that they were in a corresponding acoustic environment for a whole work day. In order to avoid reading or working disturbance, it could be recommended to limit the background sound level under $37 \mathrm{~dB}(\mathrm{~A})$. It is interesting to note that in France, acoustic regulation demands that the background sound level does not exceed $35 \mathrm{~dB}(\mathrm{~A})$ due to inside building equipment [51].

\subsection{Comprehension rate}

Finally, the comprehension rate was influenced by the background sound level. There is a large literature on the effect of noise on task performance of school pupils, but less for adults with the reading comprehension rate. Chitwood and Vaughn [52] found that there is no influence of the type of background noise (silence, lyrical music and pink noise) on reading comprehension for young adults, but in their study, the sound levels were not controlled as the experiment was carried out on line, through a website with personal headphones.

\subsection{Limitations}

A first limitation to this study concerns the design of the sound sequences. The study focused on a context of disturbance at home with the windows closed, which may explain the low sound levels of the sound scenes. It would be interesting in a future study to design an experiment around a corpus of open window sound scenes, which would increase the sound level and the resulting measured disturbance levels. It would be also necessary to respect the feeling of pass-by from one side to the other with stereo recordings (without SimScene simulator) or with spatial effect with the VBAP system of the laboratory. Furthermore, it would be interesting to introduce more variability in the noise peaks, in terms of spectral content and temporal variability, in order to simulate the real variability of road traffic in a residential area subject to noise emergence.

In addition, the designed experimental set-up is interesting to study the cognitive impact of car pass-bys, evaluated with the time needed to read a line of a text and with the comprehension rate. This design is less interesting for the study of the reading disturbance due to fluctuating sounds because it is already well established that the sound level is the first factor which creates disturbance [53-55]. In this configuration with the control of $L_{\text {Amax }}$, the influence of 
the number of peaks on reading disturbance could not be revealed, because it is masked by the variation of the background sound level, covariate with the emergence of peaks $(+15 \mathrm{~dB}(\mathrm{~A})$ between the smallest and the highest background noise level as well as $+15 \mathrm{~dB}(\mathrm{~A})$ for levels of emergences variations), which is much higher than the variations of sound levels due to the increase of the number of peaks (maximum $+4 \mathrm{~dB}(\mathrm{~A})$ between one and four passbys). Vogt already showed that in laboratory, the number variation of events (aircraft flyovers in his study) affected the subjective responses of annoyance less than the sound level variation [56].

The second limitation to the study concerns the tasks demanded to participants. The reading task was indeed initially built for children. Hence it was maybe too simple to observe a pronounced disturbance among experienced readers. Placing participants in a larger discomfort zone, with a more complex cognitive task, and more disturbing sound scenes, would amplify the effects observed in this study. This will be the subject of a future study.

\section{Conclusion and outlook}

This experiment was able to reveal impacts of road traffic noise with car pass-bys on cognitive performances. When the sound level does not vary like in the background noise, and for low sound levels in the range of $23 \mathrm{~dB}(\mathrm{~A})$ to $37 \mathrm{~dB}$ (A), the reading time does not depend on the sound level itself. When the sound level is fluctuating, the time needed to read a line increases during the rising front of a peak, and goes back to the former regular reading speed during the descending front. Globally, this increase equals to $8.8 \%$ whatever the noise sensitivity, but reaches $14 \%$ for slow readers. Consequently, this reading slowdown is not due to the value of the sound pressure level itself, but to the increase in the sound pressure level.

The influence of noise sensitivity and reading fluency on reading disturbance is characterized by a higher disturbance for slow readers compared to fast reader, and higher disturbance for noise sensitive persons compared to nonsensitive persons. This higher reading disturbance for slow readers is associated with a reading slowdown in the rising front of the peaks. The influence of the acoustic indicators is very small compared to the influence of personal factors. There is even no influence of the number of events on the reading disturbance.

In order to go further in this topic, it would be interesting to test the impact of the characteristics of the peak, such as the slope of the rising front or the duration of the peak, on the reading speed. The experiment protocol would have to be longer, with longer sequences built with more passbys. It would be also possible to study the speed of the reading during the installed peaks if these ones would last longer, studying train pass-bys instead of car pass-bys for example. The text to be read could be longer too, but maybe more difficult, keeping the idea of calibrating the difficulty of each line of text. Another tool that could be useful for further experiments is the eye-tracker, which allows analysing not only the reading speed in real time but also possible eye retro-saccades during noise peaks. The study of the pupil dilation could also be associated to the physiological impact of the emergence of a peak [57, 58]. It is also important to increase the number of participants in order to have at least 30 persons in each sub-group of sensitivity and reading ability.

In order to increase the impacts on disturbance, it could be interesting to virtually open the windows to increase the background sound level, to include feeling of spatial vehicle movements, but also to modify the perception question that was focused on acute reading disturbance due to sound in this experiment. It would be interesting to ask for overall annoyance as these ratings could be higher than reading disturbance [59]. Kurra et al. [60] even observed that the range of the annoyance scale is increased if the question concerns the home projected annoyance due to the sound environment and not the overall annoyance.

Finally, the same experiment could be carried out again but instead of choosing control on $L_{\mathrm{Amax}}$, the equalization could be on $L_{\mathrm{A} 90}$, or on $L_{\mathrm{Aeq}}$. With such a design, the analysis could give more results on the impact of the level of emergence and of the number of peaks on perceived disturbance.

\section{Data availability statement}

Data are available on request from the authors.

\section{Conflict of interest}

Authors declared no conflict of interests.

\section{References}

1. WHO: Burden of disease from environmental noise: quantification of healthy life years lost, F. Theakston, Ed., World Health Organization, Regional Office for Europe, Copenhagen. 2011.

2. H.M.E. Miedema, C.G. Oudshoorn: Annoyance from transportation noise: Relationships with exposure Metrics DNL and DENL and their confidence intervals. Environmental Health Perspectives 109 (2001) 409-416.

3. Science for Environment Policy: Future brief: Noise abatement approaches. Produced for the European Commission DG Environment by the Science Communication Unit, UWE, Bristol, 2017. Available on the 8th of March 2021 at: http://ec.europa.eu/science-environment-policy.

4. T. Kaczmarek, A. Preis: Annoyance of time-varying roadtraffic noise. Archives of Acoustics 35, 3 (2010) 383-393. https://doi.org/10.2478/v10168-010-0032-2.

5. R. Guski, D. Schreckenberg, R. Schuemer: WHO Environmental Noise Guidelines for the European Region: A Systematic Review on Environmental Noise and Annoyance. International Journal of Environmental Research and Public Health 14, 12 (2017) 1539. https://doi.org/10.3390/ ijerph14121539.

6. A. Can, L. Leclercq, J. Lelong, J. Defrance: Capturing urban traffic noise dynamics through relevant descriptors. Applied Acoustics 69, 12 (2008) 1270-1280. https://doi.org/10.1016/ j.apacoust.2007.09.006. 
7. P. Lercher, A. Bockstael, B. De Coensel, L. Dekoninck, D. Botteldooren: The application of a notice-event model to improve classical exposure-annoyance estimation. Journal of the Acoustical Society of America 131, 4 (2012) 3223-3223. https://doi.org/10.1121/1.4708019.

8. S.E. Samuels, J. Parnell: Peak noise events occurring in road traffic noise, in Proceedings of Acoustics 2004, Gold Coast, Australia. 2004.

9. L.A. Gille, C. Marquis-Favre, A. Klein: Noise annoyance due to urban road traffic with powered-two-wheelers: Quiet periods, order and number of vehicles, Acta Acustica United with Acustica 102, 3 (2016) 474-487. https://doi.org/ 10.3813/AAA.918966.

10. J.M. Wunderli, R. Pieren, M. Habermacher, D. Vienneau, C. Cajochen, N. Probst-Hensch, M. Röösli, M. Brink: Intermittency ratio: A metric reflecting short-term temporal variations of transportation noise exposure. Journal of Exposure Science \& Environmental Epidemiolog 26, 6 (2016) 575-585. https://doi.org/10.1038/jes.2015.56.

11. M. Brink, B. Schäffer, D. Vienneau, M. Foraster, R. Pieren, I. C. Eze, C. Cajochen, N. Probst-Hensch, M. Röösli, J.M. Wunderli: A survey on exposure-response relationships for road, rail, and aircraft noise annoyance: Differences between continuous and intermittent noise. Environment International 125 (2019) 277-290.

12. J. Haubrich, S. Benz, M. Brink, R. Guski, U. Isermann, B. Schäffer, R. Schmid, D. Schreckenberg, J.M. Wunderli: Leq + X: Re-Assessment of exposure-response relationships for aircraft noise annoyance and disturbances to improve explained variance, in Proceedings of the ICA, 23rd International Congress on Acoustics, Aachen, Germany. 2019.

13. H. Héritier, D. Vienneau, M. Foraster, I. Collins Eze, E. Schaffner, L. Thiesse, F. Rudzik, M. Habermacher, M. Köpfli, R. Pieren, M. Brink, C. Cajochen, J.M. Wunderli, N. Probst-Hensch, M. Röösli: Transportation noise exposure and cardiovascular mortality: A nationwide cohort study from Switzerland. European Journal of Epidemiology 32, 4 (2017) 307-315. https://doi.org/10.1007/s10654-0170234-2.

14. M. Brink, P. Lercher, A. Eisenmann, C. Schierz: Influence slope of of rise and event order of aircraft noise events on high resolution actimetry parameters. Somnologie 12 (2008) 118128. https://doi.org/10.1007/s11818-008-0345-9.

15. R. Guski, U. Felscher-Suhr, R. Schuemer: The concept of noise annoyance: How international experts see it. Journal of Sound and Vibration 223, 4 (1999) 513-527. https://doi.org/ 10.1006/jsvi.1998.2173.

16. D. Ouis: Annoyance from Road Traffic noise. Journal of Environmental Psychology 21, 1 (2001) 101-120. https://doi.org/10.1006/jevp.2000.0187.

17. K. Paunović, B. Jakovljević, G. Belojević: Predictors of noise annoyance in noisy and quiet urban streets. Science of the Total Environment 407, 12 (2009) 3707-3711. https://doi. org/10.1016/j.scitotenv.2009.02.033.

18. H.M.E. Miedema: Annoyance caused by environmental noise: Elements for evidence-based noise policies. Journal of Social Issues 63, 1 (2007) 41-57. https://doi.org/10.1111/ j.1540-4560.2007.00495.x.

19. P. Lercher: Noise in cities: Urban and transport planning determinants and health in cities, in Integrating Human Health into Urban and Transport Planning, M. Nieuwenhuijsen, H. Khreis, Eds., Springer International Publishing, Cham. 2019, pp. 443-481.

20. S. Versümer, J. Steffens, P. Blättermann, J. Becker-Schweitzer: Modeling evaluations of low-level sounds in everyday situations using linear machine learning for variable selection. Frontiers in Psychology 11 (2020) 2593. Available on the 8th of March
2021 at https://www.frontiersin.org/article/10.3389/fpsyg. 2020.570761.

21. D. Schreckenberg, C. Belke, J. Spilski: The development of a multiple-item annoyance scale (MIAS) for transportation noise annoyance. International Journal of Environmental Research and Public Health 15 (2018) 971. https://doi.org/ 10.3390/ijerph15050971.

22. M.R. Vasilev, J.A. Kirkby, B. Angele: Auditory distraction during reading: A Bayesian meta-analysis of a continuing controversy. Perspectives on Psychological Science 13, 5 (2018) 567-597. https://doi.org/10.1177/1745691617747398.

23. J.L. Szalma, P.A. Hancock: Noise effects on human performance: A meta-analytic synthesis. Psychological Bulletin 137, 4 (2011) 682-707. https://doi.org/10.1037/a0023987.

24. J.R. Wessel, A.R. Aron: Unexpected events induce motor slowing via a brain mechanism for action-stopping with global suppressive effects. Journal of Neuroscience 33, 47 (2013) 18481-18491. https://doi.org/10.1523/JNEUROSCI. 3456-13.

25. R. Dedieu, C. Lavandier, C. Camier, S. Berger: Evaluation du confort acoustique en logement résidentiel冈: Description du système de reproduction sonore adapté aux expériences perceptives envisagées, in Proceedings of the French Congress of Acoustics, Le Havre. 2018.

26. V. Pulkki: Virtual sound source positioning using vector base amplitude panning. Journal of the Audio Engineering Society 45, 6 (1997) 456-466.

27. M. Rossignol, G. Lafay, M. Lagrange, N. Misdariis: SimScene: A web-based acoustic scenes simulator, in Proceedings of the Web Audio Conference, IRCAM, Paris France. 2014.

28. J. Terroir, C. Lavandier: Perceptual impact of distance on high-speed train sound quality. Acta Acustica United with Acustica 100, 2 (2014) 328-340. https://doi.org/10.3813/ AAA.918712.

29. A. Pate, C. Lavandier, A. Minard, I. Le Griffon: Perceived unpleasantness of aircraft flyover noise: Influence of temporal parameters. Acta Acustica United with Acustica 103 (2017) 34-47. https://doi.org/10.3813/AAA.919031.

30. S. Guéraud, C. Royer: On-line investigations of inference production in skilled and less-skilled ten years old children, in 26th Annual Meeting of the Society for Text and Discourse, Kassel, Germany. 2016.

31. H. Guinet, C. Royer, H. Labat, S. Guéraud: Inferential processes in 8 to 10 years old children. New factors which may explain development, in 22th Annual Meeting of Society for the Scientific Study of Reading, Newport Beach (USA). 2020. [postponed to 2022].

32. M. Schutte, S. Sandrock, B. Griefahn: Factorial validity of the noise sensitivity questionnaire. Noise Health 9, 37 (2007) 96-100. https://doi.org/10.4103/1463-1741.37425.

33. B. Griefahn: Determination of noise sensitivity within an internet survey using a reduced version of the noise sensitivity questionnaire. Journal of the Acoustical Society of America 123, 5 (2008) 3449.

34. W.H. Kruskal, W.A. Wallis: Use of ranks in one-criterion variance analysis. Journal of the American Statistical Association 47, 260 (1952) 583-621. https://doi.org/10.2307/ 2280779 .

35. D.F. Bauer: Constructing confidence sets using rank statistics. Journal of the American Statistical Association 67, 339 (1972) 687-690. https://doi.org/10.1080/01621459.1972. 10481279 .

36. M. Hollander, W. Douglas: Nonparametric Statistical Methods. John Wiley and Sons, New York, 1973, pp. 139-146.

37. P. Nemenyi: Distribution-free Multiple Comparisons. PhD Dissertation, Princeton University, 1963. 
38. J.J. Hox: Multilevel Analysis: Techniques and Applications. Second edition, Routledge, New York, 2010.

39. T.A. Van Dijk, W. Kintsch: Strategies of Discourse Comprehension. Academic Press, New York, 1983.

40. D. Bates, M. Malcher, B. Bolker, S. Walker: Fitting linear mixed-effect models using lme4. Journal of Statistical Software 67 (2015) 1-48.

41. A. Trollé, C. Marquis-Favre, A. Klein: Short-term annoyance due to tramway noise: Determination of an acoustical indicator of annoyance via multilevel regression analysis. Acta Acustica United with Acustica 100, 1 (2015) 34-45. https://doi.org/10.3813/AAA.918684. Corrigendum to short-term annoyance due to tramway noise: Determination of an acoustical indicator of annoyance via multilevel regression analysis, Acta Acustica United with Acustica, 101(1): 205-205, 2015. https://doi.org/10.3813/AAA.918819.

42. L.A. Gille, C. Marquis-Favre, R. Weber: Aircraft noise annoyance modeling: Consideration of noise sensitivity and of different annoying acoustical characteristics. Applied Acoustics 115 (2017) 139-149. https://doi.org/10.1016/j. apacoust.2016.08.022.

43. S. Kurra, M. Morimoto, Z.I. Maekawa: Transportation noise annoyance - A simulated environment study for road, railway and aircraft noises, Part 2: Activity disturbance and combined results. Journal of Sound and Vibration 220, 2 (1999) 279-295.

44. S. Kuhnt, C. Schürmann, M. Schütte, E. Wenning, B. Griefahn, M. Vormann: Modelling annoyance from combined traffic noises: An experimental study. Acta Acustica United with Acustica 94, 3 (2008) 393-400. https://doi.org/ 10.3813/AAA.918047.

45. J.F. Park, M.C. Payne: Effects of noise level and difficulty of task in performing division. Journal of Applied Psychology 47, 6 (1963) 367-368. https://doi.org/10.1037/h0048773.

46. A. Trollé, J. Terroir, C. Lavandier, C. Marquis-Favre, M. Lavandier: Impact of urban road traffic on sound unpleasantness: A comparison of traffic scenarios at crossroads. Applied Acoustics 94 (2015) 46-52. https://doi.org/ 10.1016/j.apacoust.2015.02.008.

47. J.J. Walczyk: The interplay between automatic and control processes in reading. Reading Research Quarterly 35, 4 (2000) 554-566.

48. W. Schneider, R.M. Shiffrin: Controlled and automatic human information processing: Detection, search, and attention. Psychological Review 84, 1 (1977) 1-66. https://doi. org/10.1037/0033-295X.84.1.1.
49. M.T.H. Chi: Two approaches to the study of experts characteristics, in The Cambridge Handbook of Expertise and Expert Performance, K.A. Ericsson, N. Charness, P.J. Feltovitch, R.R. Hoffman, Eds., Cambridge University Press, Cambridge, UK. 2006.

50. V. Hongisto, D. Oliva, L. Rekola: Subjective and objective rating of spectrally different pseudorandom noises - Implications for speech masking design. Journal of Acoustical Society of America 137, 3 (2015) 1344-1355. https://doi.org/ $10.1121 / 1.4913273$.

51. Arrêté du 30 juin 1999 relatif aux caractéristiques acoustiques des bâtiments d'habitation, (French order relating to the acoustic characteristics of residential buildings). 1999.

52. M. Chitwood, K. Vaughn: Cognitive performance and sounds: The effects of lyrical music and pink noise on performance. The NKU Journal of Student Research 1 (2018) 9-14.

53. B. De Coensel, D. Botteldooren, B. Berglund, M. Nilsson, T. De Muer, P. Lercher: Experimental investigation of noise annoyance caused by high-speed trains. Acta Acustica United with Acustica 93 (2007) 589-601.

54. T. Kaczmarek, A. Preis: Annoyance of time-varying roadtraffic noise. Archives of Acoustics 35, 3 (2010) 383-393.

55. J. Morel, C. Marquis-Favre, D. Dubois, M. Pierrette: Road traffic in urban areas: A perceptual and cognitive typology of pass-by noises. Acta Acustica United with Acustica 98, 1 (2012) 166-178. https://doi.org/10.3813/AAA.918502.

56. J. Vogt: The relative impact of aircraft noise and number in a full factorial laboratory design. Journal of Sound and Vibration 282 (2005) 1085-1100.

57. J. Klingner: Measuring cognitive load during visual tasks by combining pupillometry and eye tracking. Dissertation in partial fulfillment of the requirements for the degree of doctor of philosophy, 2010, p. 116.

58. A.A. Zekveld, T. Koelewijn, S.E. Kramer: The pupil dilation response to auditory stimuli: Current state of knowledge. Trends in Hearing 22 (2018). https://doi.org/10.1177/ 2331216518777174

59. J. Lambert, P. Champelovier, R. Blanchet, C. Lavandier, J. Terroir, F. Marki, B. Griefhan, U. Iemma, K. Janssen, R. Bisping: Human response to simulated airport nois scenarios in home-like environments. Applied Acoustics 90, 1 (2015) 116-125.

60. S. Kurra, M. Morimoto, Z.I. Maekawa: Transportation noise annoyance - A simulated environment study for road, railway and aircraft noises, part 1: Overall annoyance. Journal of Sound and Vibration 220, 2 (1999) 251-278.

Cite this article as: Lavandier C. Regragui M. Dedieu R. Royer C. \& Can A, et al.. 2022. Influence of road traffic noise peaks on reading task performance and disturbance in a laboratory context. Acta Acustica, 6, 3. 